\title{
LETTERS
}

Send your letters to the editor, British Dental

Journal, 64 Wimpole Street, London W1G 8YS

E-ail bdj@bda dentistry.org.uk

Priority will be given to letters less than 500

words long. Authors must sign the letter,

which may be edited for reasons of space

\section{A fair fee?}

Sir,- I would like to comment further on the points raised by your correspondent $\mathrm{C}$. Daniels, (BDJ 2003; 194: 466) regarding the annual retention fee for specialist lists. As he correctly points out, specialist lists are of value to the profession as a whole.

He also highlights the fact that some of the individuals on the specialist lists were accepted under grandparenting clauses, rather than by virtue of them having undergone formal training. Antony Townsend, responding on behalf of the GDC, attempted to justify the higher specialist fees with reference to the transition and set-up costs, particularly the conduct of appeals. It is reasonable to assume that the vast majority of appeals would have related to practitioners who, to quote your previous correspondent, 'would not be recognised as specialists in any other country'.

There will, of course, be differing opinions as to whether this was appropriate, and I do not wish to enter into that particular debate. Nevertheless, the GDC were effectively inviting practitioners who were generalists, and who would not automatically have qualified for specialist status, to be considered for inclusion on the lists; this only lends further weight to the argument that the set-up costs should have been borne by the profession as a whole.

Mr Townsend goes on to suggest that, now the transition period is nearing completion, a lower fee may be paid in the future. Again, one might argue why the transition costs for these arrangements, which will presumably now be in operation for many years, should be incurred just by one generation of specialists. With regard to his further point, about there being only two feepaying specialties, I understand this is simply due to legislation not permitting fees to be levied on specialties which are at present only recognised within the UK.

One presumes that the non-fee paying specialties currently enjoy all the advantages (if indeed there are any) of those who do pay. Would it be too much to hope that, when legislation finally allows the GDC to levy a fee on all specialties, initial fee levels for those that are currently 'free of charge' will also reflect their notional contribution to the transitional costs, and thus allow the others to be recompensed?

It is noteworthy that the General Medical Council does not feel it necessary to charge additional fees, despite having a vastly increased number of specialties, with all the complexity that that entails. It is not the actual amount of money at stake which is my main concern, but rather the principle. The GDC appears to have adopted a policy that they think they can get away with, rather than one which is equitable. I remain unconvinced by $\mathrm{Mr}$ Townsend's arguments, and I suspect that a lot of my orthodontic specialist colleagues will feel the same way.

\section{J. W. Ferguson}

Walsall

doi: 10.1038/sj.bdj.4810367

\section{Solution for halitophobics}

Sir,- While many patients genuinely suffer from halitosis, halitophobia, an exaggerated fear of having bad breath, should be considered if no clinical findings support the patient's complaints or if the patient persists in believing that they have halitosis after treatment for genuine halitosis or pseudo halitosis ${ }^{1}$.

At times it becomes difficult for dentists to manage such patients. Referring such patients to a clinical psychologist or psychiatrist is an option, but this is not acceptable to all patients because they believe that they have severe malodour ${ }^{2}$ and also due to the social stigma attached to visiting a psychiatrist. 'Organoleptic' or 'hedonic' assessment has been considered as a kind of reference standard ${ }^{3}$ and the most practical method ${ }^{4}$ of oral malodour measurement. Such patients can be helped by using a simple 'air bag' method.

This should be done only after the patient is diagnosed to be suffering from pseudo halitosis or halitophobia. A food grade thin transparent plastic bag (odourless) measuring approximately $8 \mathrm{x}$
12 inches is used. The halitophobic patient is asked to seal his mouth with the open end of plastic bag. They then inhale air through the nose and exhale through the mouth in short bursts, as in speaking. The procedure is continued till the plastic bag is fully inflated. The mouth of this plastic air filled bag is then held tight so that no air escapes out of it. Next, the patient is seated comfortably in a well ventilated odour free room. Air from the plastic bag should be squeezed out in front of the patients' nose while they inhale slowly. As the air is odour free, the patient should be convinced that they are not suffering from halitosis.

To further strengthen the belief, odour free air can be collected from a volunteer or relative of the patient and the procedure be repeated for comparison. The advantage of this method is that a stream of the exhaled air is available for longer duration to be sniffed by the patient.

Another advantage of this method is the way in which air is collected; which is by short bursts, similar to speaking. We generally notice bad breath while someone is talking. Hence this air bag organoleptic self-assessment method can be used as adjunct in the management of patients with pseudo halitosis or halitophobia.

\section{S. Setty}

\section{Manipal, India}

doi: $10.1038 /$ sj.bdj.4810368

1. Murata T, Yamaga T, Lida T et al. Classification and examination of halitosis. Int Dent J 2002 52:181-186.

2. Coil J M, Yaegaki K, et al. Treatment Needs (TN) and practical remedies for halitosis. Int Dent J 2002 52:187-191.

3. Rosenberg M McCulloch C A G. Measurement of ora malodor: Current Methods and Future Prospects. J Perio 1992 63:776-782.

4. Yaegaki K, Coil J M. Examination, Classification, and Treatment of Halitosis; Clinical Perspectives. J Can DentAssoc 2000 66: 257-266

\section{Web-based learning}

Sir,- The letter from Dr Yeung on webbased learning (BDJ 2003; 194: 409 ) refers to the fact that dentistry is way behind other professionals in the use of web-based learning. However there are exceptions. Alpha Omega International 
Dental Fraternity is the only international dental organisation to offer webcasts to its members as far as we know. These webcasts are timed to be viewed simultaneously by members across the world and are free of charge through our website. The topics are varied and on completion of a multiple-choice paper at the end of the lecture qualify for two hours CPD. Groups of members often come together to view the webcast and questions can be e-mailed in to the lecturer during the webcast. The webcasts are currently only available to members but we intend to offer access to nonmembers in the future on payment of an appropriate fee. The webcast programme is ongoing and is published on the Fraternity's website at www.ao.org. J. Wolffe

London

doi: 10.1038/sj.bdj.4810369

\section{Significant complications of doxycycline}

Sir,- In my role as $B D J$ Adviser on

Abstracts, I recently drew attention to the first reports of the serious complication of intracranial hypertension arising from doxycycline therapy (BDJ 2003; 194: 491). This had significant ocular effects, and occurred after three weeks' therapy in one reported case. Since writing that abstract, I have seen someone who developed a marked diplopia on the fourth day of a doxycycline course at $100 \mathrm{mg}$ per day. This resolved on cessation of the drug.

Tetracyclines have been used for many years in relation to periodontal problems, but with minimal reported adverse effects. It is important that dentists are aware of the occasional severe complications which may occur, and advise patients accordingly of the significance of headaches and ocular symptoms.

\section{T. L. P. Watts}

London

doi: 10.1038/sj.bdj.4810370

\section{Candida-induced stomatopyrosis}

Sir,- In the abstract section of the journal, (BDJ 194: 607) Dr Trevor Watts has produced an abstract of Candida-induced stomatopyrosis and its relation to diabetes mellitus ${ }^{1}$ but has incorrectly referred to burning mouth syndrome, instead of burning mouth symptoms (or stomatopyrosis) throughout. Whilst this may seem a trivial point to raise it is in fact the whole point of the original article. Burning mouth syndrome may be defined as pain present when no underlying dental or medical causes are identified ${ }^{2}$.

In the original paper the authors are careful to use the phrase burning mouth sensations which are present secondary to candida species, encouraged in patients with type 2 diabetes. Obviously an underlying cause has been identified, so the diagnosis cannot be burning mouth syndrome. The authors are clear on this.

I am sure there is confusion in the minds of some $B D J$ readers between burning mouth sensations, burning mouth symptoms and burning mouth syndrome. The abstract summary by Dr Watts does nothing to clarify this confusion, but merely adds to it.

\section{P. A. Atkin}

London

1. Vltkov L, Weltgasser R, et al. Candida-induced stomatopyrosis and its relation to diabetes mellitus. $J$ Oral Pathol Med 2003 32:46-50

2. Zakrzewska J M, Glenny A M, Forssell H. Interventions for the treatment of burning mouth syndrome (Cochrane Review). In The Cocbrane library, issue 2. 2003. Oxford: Update Software

Trevor Watts, BDJ Adviser on Abstracts responds: Dr Atkin raises an interesting point. However, the current MEDLINE description of burning mouth syndrome is: 'A group of painful oral symptoms associated with a burning or similar sensation. There is usually a significant organic component with a degree of functional overlay; it is not limited to the psychophysiologic group of disorders.' At least one authoritative source therefore disagrees with Dr Atkin on the definition of burning mouth syndrome. I agree with Dr Atkin that there is confusion over burning mouth symptoms. However, I included the abstract to warn dentists of the link with developing or established Type 2 diabetes. Abstracts are necessarily limited, and readers may always consult the original paper.

doi: 10.1038/sj.bdj.4810371

\section{Clean as a whistle}

Sir,- It is not that unusual to be surprised by the answer a patient can give in response to a question from a dental professional. However, when our practice hygienist enquired from a patient how she was getting on with her cleaning, we were all rather taken aback by the response 'Quite well really, I've just done the kitchen and the bedroom and I finished the conservatory at 5.00 last night, but I've still got to do the downstairs loo'. We considered it inappropriate to advise on a suitable hygiene aid for the latter task.

\section{S. P. E Tucker}

Suffolk

doi: 10.1038/sj.bdj.4810372 